\title{
09.1
}

\section{Фото- и термоиндуцированные центры окраски в керамике $\mathrm{TiO}_{2}$}

\author{
(С Н.И. Глазкова, В.Н. Кузнецов, Р.В. Михайлов
}

Санкт-Петербургский государственный университет

E-mail: nadezhda.glazkova@spbu.ru

Поступило в Редакцию 26 мая 2016 г.

С помощью камеры-криостата, разработанной для спектрофотометра, снабженного интегрирующей сферой, исследованы центры окраски (ЦО) в фотохромной керамике диоксида титана, индуцированные облучением в УФ- и видимой области спектра, выявлен канал образования и уничтожения ЦО при восстановительно-окислительной обработке и обнаружен эффект температурноиндуцированного роста поглощения центров.

DOI: $10.21883 /$ PJTF.2017.05.44360.16343

Исследование центров окраски (ЦО) в твердых телах (т.е. собственных и/или примесных точечных дефектов, поглощающих излучение в видимой области спектра), определяющих многие электронные и оптические свойства легированных материалов, остается актуальным многие десятилетия. Возможности изучения ЦО в твердых телах существенно расширяются при проведении оптических измерений in situ в широком диапазоне температур, в условиях, обеспечивающих создание и уничтожение ЦО, а также контроль кинетики этих процессов. ЦО в непрозрачных твердых телах (порошках, керамике) исследуют методом спектроскопии диффузного отражения (ДО) с помощью спектрофотометров, снабженных интегрирующей сферой. Измерения ДО при различных температурах в вакууме и газовых средах предполагают помещение образца в специальную камеру, которая обеспечивала бы указанные условия и наименьшие потери отраженного излучения.

Задача данной работы - продемонстрировать перспективы использования камеры-криостата, сконструированного в лаборатории, для исследования ЦО в твердых телах на примере результатов, полученных для фотохромной керамики диоксида титана.

Камера, разработанная для спектрофотометра Carry 5000, снабженного интегрирующей сферой, является криостатом типа „образец 
в вакууме “ и изготовлена из нержавеющей стали. Кожух камеры в виде стакана приварен к сверхвысоковакуумному фланцу Ду35 C31M. K ответному фланцу приварен L-образный полый трубчатый палец, размещенный внутри кожуха и являющийся резервуаром для жидкого азота. В нижней части кожуха расположен фланец для вакуумного уплотнения кварцевого окна. Образец диаметром $16 \mathrm{~mm}$, укрепленный на торце L-образного пальца, находится на расстоянии $4 \mathrm{~mm}$ от окна и $9 \mathrm{~mm}$ от интегрирующей сферы, что обеспечивает сбор $\sim 70 \%$ отраженного образцом света. Нагреватель мощностью $45 \mathrm{~W}$, помещенный в L-образный палец, обеспечивает нагрев образца до $720 \mathrm{~K}$ в вакууме или в газовой среде. В данной работе вакуум $\left(10^{-4}\right.$ Torr $)$ поддерживается откачкой малогабаритным цеолитовым насосом. Камера-криостат вместе с компактной вакуумной системой может перемещаться из положения для облучения образца в положение для оптических измерений.

Камеру-криостат апробировали на образце керамики $\mathrm{TiO}_{2}$ толщиной $570 \mu \mathrm{m}$, полученном окислением технического титана (99.4 at.\% Ti) в атмосфере муфельной печи при $875^{\circ} \mathrm{C}$ в течение $40 \mathrm{~h}$. По данным рентгеноструктурного анализа синтезированный $\mathrm{TiO}_{2}$ содержал только фазу рутила. Результаты характеризации образца различными методами подробно описаны в работе [1]. Полученный образец $\mathrm{TiO}_{2}$ имел желтую окраску и отчетливо выраженные фотохромные свойства. После облучения на воздухе в УФ- или видимой области спектра у синтезированного образца $\mathrm{TiO}_{2}$ появлялось дополнительное поглощение в видимой области, которое полностью исчезало в результате прогрева на воздухе при $570 \mathrm{~K}$. In situ обработка фотохромного рутила и измерение его спектров ДО при различных температурах в вакууме и в присутствии кислорода позволили получить спектры поглощения ЦО, наводимого при восстановлении, и темновой обратимой термоактивации.

Спектры ДО $R(\lambda)$ измеряли в области 300-2500 nm с помощью камеры-криостата и спектрофотометра Cary 5000, снабженного интегрирующей сферой. Спектры поглощения $A(h v)$ рассчитывали как разность спектра отражения эталона(Spectralon) и спектра отражения образца, а спектры индуцированного поглощения $\Delta A(h v)$ - как разность спектров ДО, зарегистрированных до $R_{1}(h v)$ и после $R_{2}(h v)$ воздействия.

На рис. 1 представлены спектры поглощения (разностные спектры ДО), наводимого в керамике $\mathrm{TiO}_{2}$ монохроматическим облучением в вакууме в течение $10 \mathrm{~min}$ в УФ- (кривая 1) и видимой области спектра (кривые 2-4) при $T=90 \mathrm{~K}$. На рис. 1 спектры приведены 


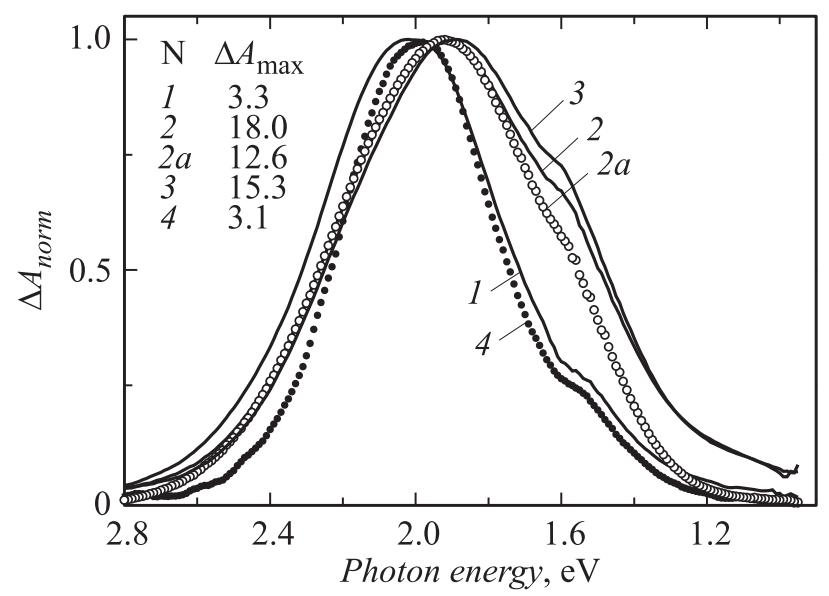

Рис. 1. Нормированные спектры поглощения (разностные спектры ДО), индуцированного в керамике $\mathrm{TiO}_{2}$ облучением светом с $h v=3.4 \mathrm{eV}(1)$, $3.05 \mathrm{eV}(2,2 a), 2.75 \mathrm{eV}(3)$ и $2.33 \mathrm{eV}(4)$ при $T=90 \mathrm{~K}(1-4)$ и $T=290 \mathrm{~K}(2 a)$. Приведены номера кривых и максимальные значения поглощения, на которые нормированы спектры.

в нормированном на максимальное значение поглощения $\Delta A_{\max }$ виде. Из рис. 1 видно, что все спектры фотоиндуцированного поглощения имеют максимум в области $1.9-2.0 \mathrm{eV}$ и плечо при $\sim 1.6 \mathrm{eV}$, при этом по амплитуде $\left(\Delta A_{\max }\right)$ спектры различаются в 5-6 раз. Наиболее эффективным оказывается облучение вблизи края собственного поглощения рутила при $h v=3.05 \mathrm{eV}$. Из рис. 1 следует также, что спектры поглощения, наводимые при комнатной температуре (кривая 2a) и $T=90 \mathrm{~K}$ (кривая 2) по форме различаются мало. Спектры поглощения, представленные на рис. 1, принадлежат ЦО, которые образуются при фотовозбуждении $\mathrm{TiO}_{2}$ как в области собственного поглощения $(h v=3.4 \mathrm{eV})$, так и в области поглощения дефектов, определяющих желтую окраску керамики.

Впервые ЦО в $\mathrm{TiO}_{2}$, поглощающие в видимой $(\sim 2.0 \mathrm{eV})$ области спектра, были обнаружены в N-допированном анатазе после облучения в УФ- и видимой области спектра при $T=290 \mathrm{~K}$ в вакууме, кислороде или водороде [2]. Фотоиндуцированные ЦО в $\mathrm{N}$-допированном $\mathrm{TiO}_{2}$ [2] и

Письма в ЖТФ, 2017, том 43, вып. 5 
фотохромной керамике [1] были отнесены к центрам $\mathrm{Ti}^{3+}$. Фотообразование таких центров в обеих модификациях $\mathrm{TiO}_{2}$ надежно установлено методом электронного парамагнитного резонанса (ЭПР) [3].

Голубую окраску восстановленного номинально чистого $\mathrm{TiO}_{2}$ также связывают с центрами $\mathrm{Ti}^{3+}$-типа. Однако выявление отдельных полос поглощения $\mathrm{Ti}^{3+}$-центров затруднено из-за плохого разрешения спектров поглощения [4-6]. Так, в спектрах поглощения монокристаллов рутила, восстановленных прогревом в $\mathrm{H}_{2}$ [4] или бомбардировкой нейтронами [5], на фоне бесструктурного поглощения проявлялись только слабо выраженные максимумы при $1.70 \mathrm{eV}$ [4] или $1.63 \mathrm{eV}$ [5]. В спектрах поглощения синего монокристалла рутила наблюдали пять полос поглощения в ближней ИК- и в видимой области спектра при 0.34 , $0.86,1.49,2.3$ и $2.91 \mathrm{eV}[6]$, которые были отнесены к $d-d$-переходам в $\mathrm{Ti}^{3+}$-ионах и переходам с переносом заряда в $\mathrm{Ti}^{3+}-\mathrm{Ti}^{4+}$-комплексах. Однако полоса при $1.49 \mathrm{eV}$, сопоставимая по положению в спектре с плечом при $\sim 1.6 \mathrm{eV}$ на рис. 1 , имеет полуширину $1.03 \mathrm{eV}$, которая превышает полуширину спектров поглощения, показанных на рис. 1 . Полуширина наиболее широкого спектра 3 составляет $0.78 \mathrm{eV}$. Для спектров поглощения $\mathrm{Ti}^{3+}$-ионов в монокристаллах сапфира типичны две перекрывающиеся полосы при $\sim 2.5$ и $\sim 2.2 \mathrm{eV}[7,8]$, а также полоса при $1.55 \mathrm{eV}$, которую связывают с комплексами $\mathrm{Ti}^{3+}-\mathrm{Ti}^{4+}[8]$. Таким образом, отнесение ЦО, фотоиндуцированных в $\mathrm{TiO}_{2}$, к центрам $\mathrm{Ti}^{3+}$ на основании литературных спектральных данных носит сугубо качественный характер.

В связи с этим весьма результативным оказалось использование камеры-криостата для in situ высокотемпературной обработки образца в вакууме или кислороде. На рис. 2 приведены спектры поглощения, наведенного в результате двух последовательных прогревов при $720 \mathrm{~K}$ в течение $30 \mathrm{~min}$ (кривые 1 и 2), а также суммарный результат обработки (кривая 3). Спектры поглощения восстановленного образца имеют максимум при $1.9-2.0 \mathrm{eV}$ и плечо при $\sim 1.6 \mathrm{eV}$, типичные для фотоиндуцированных спектров, показанных на рис. 1 , а также плечо в области $h v<1.3 \mathrm{eV}$. Представляет интерес также спектральное проявление окисления восстановленного образца. Прогрев в $\mathrm{O}_{2}$ при $670 \mathrm{~K}$ в течение $25 \mathrm{~min}$ на $\sim 90 \%$ уничтожает ЦО, созданные при восстановлении, при этом спектры поглощения (рис. 2, кривая 3) и просветления поглощения (кривая 4) практически идентичны. Общепризнанно (см., например, [3]), что восстановление $\mathrm{TiO}_{2}$ в вакууме сопровождается 


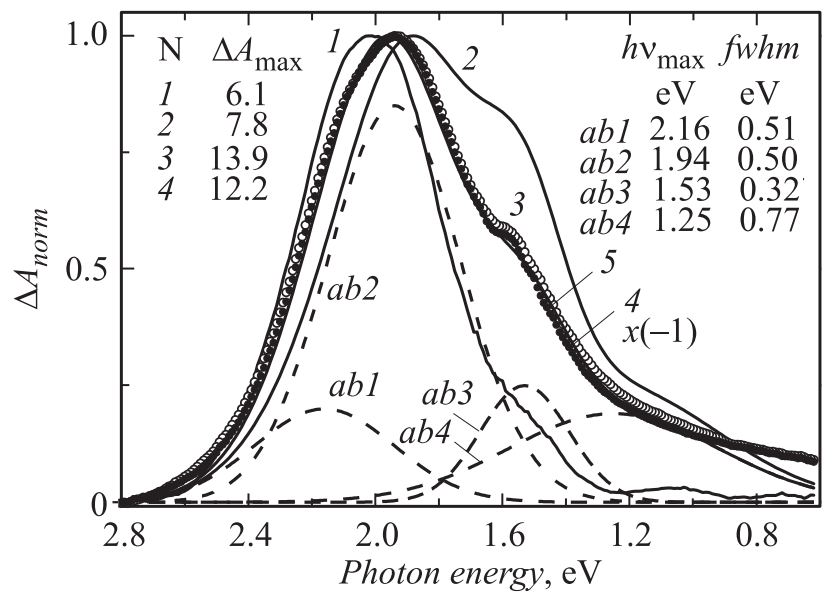

Рис. 2. Нормированные спектры поглощения, индуцированного прогревом окисленного образца керамики $\mathrm{TiO}_{2}$ в вакууме при $T=720 \mathrm{~K}$ в течение $30 \mathrm{~min}(1)$, в течение следующих $30 \mathrm{~min}(2)$, в течение $60 \mathrm{~min}$ (суммарный результат, 3), а также спектр просветления после дополнительного прогрева в $\mathrm{O}_{2}(P=1$ Torr $)$ при $670 \mathrm{~K}$ в течение $25 \mathrm{~min}$ (4). Спектр 4 приведен с обратным знаком; кривая 5 , аппроксимирующая спектр 4 , является суммой полос $a b 1, a b 2, a b 3$ и $a b 4$. Приведены номера кривых и максимальные значения поглощения, на которые нормированы спектры. Все спектры ДО были зарегистрированы при $T=290 \mathrm{~K}$.

удалением структурного кислорода и образованием кислородной вакансии, а также двух электронов, локализованных в виде $\mathrm{Ti}^{3+}$. Таким образом, отнесение фотоиндуцированных ЦО к центрам, связанным с ионами $\mathrm{Ti}^{3+}$, подтверждается обратимым изменением спектров поглощения этих ЦО при восстановлении и окислении керамики $\mathrm{TiO}_{2}$.

Кривая 5 на рис. 2 является аппроксимацией спектра просветления 4 суммой полос $a b 1-a b 4$ гауссовой формы. Параметры полос $h v_{\max }$ и полуширина (FWHM) приведены на врезке. Полоса $a b 4$ при $1.25 \mathrm{eV}$ присутствует и в некоторых спектрах фотоиндуцированного поглощения (рис. 1, кривые 2 и 3 ).

Принципиально новые сведения о центрах $\mathrm{Ti}^{3+}$ в керамике $\mathrm{TiO}_{2}$ дал обнаруженный в данной работе эффект температурного индуци-

Письма в ЖТФ, 2017, том 43, вып. 5 


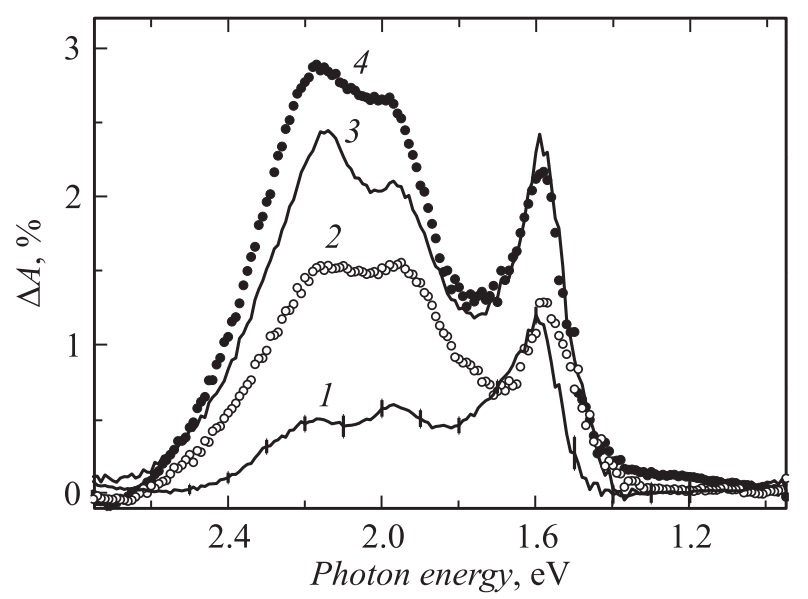

Рис. 3. Разности спектров ДО, зарегистрированных при различных температуpax (спектры температурно-индуцированного поглощения) в вакууме: $1-90$ и $290 \mathrm{~K}, 2-90$ и $420 \mathrm{~K}, 3-90$ и $485 \mathrm{~K}, 4-90$ и $520 \mathrm{~K}$. Для спектра 1 приведена погрешность усреднения по 5 разностным спектрам.

рования (ТИ) поглощения ЦО. Установлено, что в атмосфере при $290 \leqslant T \leqslant 620 \mathrm{~K}$ и в вакууме в интервале $\sim 200 \leqslant T \leqslant 520 \mathrm{~K}$ рост температуры приводит к монотонному уменьшению отражательной способности образца $R$ (в окисленном состоянии), а при снижении температуры - к полностью обратимому росту $R$. Уменьшение $R$ носит спектрально-селективный характер. Разности спектров ДО, измеренных при температурах $T_{1}$ и $T_{2}, \Delta A=R_{T 1}-R_{T 2}$, если $T_{2}>T_{1}$, показаны на рис. 3. Кривые имеют особенности при $\sim 2.16, \sim 1.97$ и $\sim 1.58 \mathrm{eV}$, которые очень близки к положению максимумов полос $a b 1, a b 2$ и $a b 3$ на рис. 2. Исходя из этого, считаем, что кривые, представленные на рис. 3 , являются спектрами ТИ поглощения $\mathrm{Ti}^{3+}{ }_{-}$центров. У окисленного образца $\mathrm{TiO}_{2}$ величина ТИ поглощения при $\sim 2.16 \mathrm{eV}$ достигает $5 \%$ при $T=520 \mathrm{~K}$ в атмосфере и $3 \%$ в вакууме (спектр 4 на рис. 3 ). В вакууме изменения $\Delta A$ полностью обратимы, если температура не превышает $\sim 520 \mathrm{~K}$, выше которой происходит восстановление образца. У восстановленного образца нагрев не приводит к регистрируемому росту поглощения, $|\Delta A| \leqslant 0.35 \%$.

Письма в ЖТФ, 2017, том 43, вып. 5 
Отличительной особенностью полос в спектрах ТИ поглощения является малая полуширина, которая оценочно составляет $0.24-0.27 \mathrm{eV}$ для полос при $\sim 2.16$ и $\sim 1.97 \mathrm{eV}$ и $\sim 0.16 \mathrm{eV}$ для полосы при $\sim 1.58 \mathrm{eV}$. Таким образом, эти полосы оказываются в $\sim 2$ раза уже, чем полосы $a b 1-a b 3$ на рис. 2, кривая 5. Такую специфику полос ТИ поглощения $\mathrm{Ti}^{3+}$-центров и его полную обратимость при снижении температуры можно связывать с вызванными нагревом искажениями кристаллического поля вблизи дефекта, включающего ионы Ті. Изучение природы обнаруженного эффекта является задачей отдельной работы.

Таким образом, использование новой камеры-криостата позволило в фотохромном $\mathrm{TiO}_{2}$ выявить оптически контролируемое образование/уничтожение центров окраски при восстановительной/окислительной обработке и обнаружить эффект обратимого температурного индуцирования их поглощения.

Работа выполнена при финансовой поддержке РФФИ (грант № 16-33-00495 мол_а). Работа Михайлова Р.В. поддержана грантом Правительства РФ для государственной поддержки научных исследований, проводимых под руководством ведущих ученых, № 14.Z50.31.0016. Авторы благодарят РЦ „Нанофотоника“ СПбГУ за содействие в проведении исследований.

\section{Список литературы}

[1] Kuznetsov V.N., Ryabchuk V.K., Emeline A.V. et al. // Chem. Mater. 2013. V. 25. P. 170-177.

[2] Emeline A.V., Sheremetyeva N.V., Khomchenko N.V. et al. // J. Phys. Chem. C. 2007 . V. 111 (30). P. 11456-11462.

[3] Chiesa M., Paganini M.C., Livraghi S., Giamello E. // Phys. Chem. Chem. Phys. 2013, V. 15. P. 9435.

[4] Lu T.-C., Wu S.-Y., Lin L.-B., Zheng W.-C. // Physica B. 2001. V. 304. P. 147-151.

[5] Lu T.-C., Lin L.-B., Wu S.-Y. et al. // Nucl. Instrum. Meth. Phys. Res. B. 2002. V. 191. P. 236-240.

[6] Khomenko V.M., Langer K., Rager H., Fett A. // Phys. Chem. Minerals. 1998. V. 25. P. 338.

[7] Grinberg M., Mandelis A., Fjeldsted K., Othonos A. // Phys. Rev. B. 1993. V. 48. P. 5922-5934.

[8] Нижанковский С.В., Сидельникова Н.С., Баранов В.В. // ФТТ. 2015. Т. 57. C. $763-767$.

Письма в ЖТФ, 2017, том 43, вып. 5 